\title{
ATRAÇÃO E RETENÇÃO DE ALUNOS CARENTES POR MEIO DE CURSOS PREPARATÓRIOS DO PROJETO AVANTE
}

Paulo Cesarde Oliveira - paulo.oliveira@ifms.edu.br

Mauro Conti Pereira-mauro.pereira@ifms.edu.br

Joelson Maschio-Joelson.maschio@ifms.edu.br

IFMS (Instituto Federal de Educação, Ciência e Tecnologia de Mato Grosso do Sul)

Rua Taquari $N 831$

79100-510 - Campo Grande, MS

Edson Antônio Batista-edson.ufms@gmail.com

UFMS (Universidade Federal de Mato Grosso do Sul)

Faculdade de Engenharia

R. UFMS, $527-J d$. Universitário

79070-900 - Campo Grande, MS

Lucas Rodrigues de Faria

Engenheiro Mecatrônico e Mecânico

Rua Camboatá 73, Santa Emília

79093-831 - Campo Grande, MS

Resumo: Este trabalho descreve como se fez para melhorar as chances de entrada $e$ permanência de alunos de periferia no IFMS. É apresentada a ação que realizada nas periferias da cidade de Campo Grande, com a criação de um curso preparatório ministrado com intuito de melhor preparar alunos desfavorecidos, principalmente, oriundos de escolas públicas, com condições socioeconômicas desfavoráveis em três localidades, na zona sul, zona norte e nas proximidades do aeroporto internacional da cidade. Estes bairros apresentam índices de criminalidade altos e são afetadas por problemas sociais como tráfico e consumo de drogas, alcoolismo e prostituição, entre outros. No entanto, mesmo nestes ambiente,s existem estudantes com potencialidades enormes, que podem ser concretizadas pela oferta deste curso de extensão, melhorando a inserção dos mesmos em escolas que ofertam ensino de qualidade como, por exemplo, os institutos federais e colégios militares. A possibilidade de acesso a um sistema de ensino bem estruturado acompanhado de infraestrutura propícia ao desenvolvimento intelectual e profissional, assim como o moral desses indivíduos pode levar a uma melhoria significativa na qualidade de vida própria e também impactar de forma significativa na conjuntura familiar.

Palavras-chave: Oportunidade. Inclusão. Educação Profissional. Aluno Carente.

\section{INTRODUÇÃO}

Este trabalho descreve o esforço de professores de um Instituto Federal de Educação, Ciência e Tecnologia em prover oportunidades de acesso, permanência e êxito a estudantes de regiões carentes da cidade onde está localizado o campus. São mostrados ainda resultados de como a vida pessoal, familiar e profissional destes alunos sai enriquecida. 
Foram ofertados cursos de extensão de matemática, língua portuguesa e conhecimentos gerais, com o objetivo de auxiliar no processo de aprendizagem, principalmente os estudantes de escolas públicas e com condições socioeconômicas desfavoráveis, e assim obter êxito no processo de seleção dos cursos técnicos integrados da instituição.

Assim, é possível sinalizar para oportunidades, pois normalmente estes estudantes estão cursando o final do ensino fundamental II e ou no primeiro ano do ensino médio e se forem estimulados a estudar, podem construir trajetórias de vida notáveis, principalmente em relação ao meio onde vivem.

Com isso é possível levar a marca IFMS para as comunidades onde o estudo seria um dos únicos caminhos para promover a ascensão social, mediante investimento em educação, ofertando um auxílio com qualidade mediante um curso preparatório, sem custo, para estudantes que certamente ficariam à margem da sociedade ou teriam mais dificuldade em ingressarem no mercado de trabalho com uma qualificação melhor, ou mesmo em fazer um curso superior.

\section{O PROBLEMA SOCIO-ECONÔMICO}

O campus Campo Grande do IFMS oferta na capital do estado de Mato Grosso do Sul três cursos técnicos na área de tecnologia: técnico em mecânica, em eletrotécnica e em informática. Os cursos técnicos do IFMS são integrados, com os alunos tendo aulas por 7 semestres em período matutino ou vespertino, tanto de disciplinas do núcleo comum (as regulares do ensino médio), bem como as 1200 horas de disciplinas técnicas, que aumentam de quantidade à medida que o aluno avança pelos semestres do curso.

Vale lembrar que existem verdadeiros talentos nas escolas públicas que, se estimulados, podem frequentar ambientes que os auxiliarão no desenvolvimento de habilidades e competências de forma plena. No IFMS existe inclusive suporte legal, com tratativas adequadas, quando envolver inovações tecnológicas no caso de registros de propriedades intelectual, publicação de produção cientifica, ensino de empreendedorismo, atividades extracurriculares, clube "Maker", ensino de línguas estrangeiras, música, fotografia e assim por diante.

Grande parte dos alunos vem de famílias e bairros carentes, com baixo nível socioeconômico. Além disso, muitos alunos de bairros mais afetados por violência, índices de criminalidade altos, tráfico de drogas e prostituição ficam em desvantagem, não tem estrutura familiar ou mesmo escolar para conseguirem passar nem no exame de ingresso na instituição.

Assim, por terem falhas na formação e não estarem acostumados à disciplina de estudar, mesmo os que conseguem ingressar, não fluem de forma adequada nos primeiros semestres dos cursos. Não é incomum ocorrer um número significativo de dependências, retenções nas componentes curriculares iniciais, assim como desistências dos estudantes nestes cursos, principalmente, devido à falta de conhecimentos básicos em matemática e língua portuguesa.

Desta forma, muitos estudantes não chegam nem a ter contato com a parte técnica e mais prática do curso, que aumenta gradativamente no decorrer dos semestres, que muito os motivariam a permanecer na instituição e terem êxito. Isto ocorre e deixam de usufruir de uma infraestrutura notável e com um corpo docente capaz de contribuir de forma significativa para a formação profissional desse público, que está numa faixa etária excelente para o aprendizado e que, se for bem conduzida, pode levar a resultados positivos tanto nos aspectos profissionais quantos nos pessoais e familiares.

Os bairros onde são realizados os cursos preparatórios se deparam com problemas desafiadores, envolvendo tráfico e consumo de entorpecentes, estudantes com baixa autoestima, também em muitos casos desinformados de oportunidades, de tal forma que a 
proposta destes cursos preparatórios é dar um suporte em conteúdo de disciplinas que são comuns em muitos concursos. Desta forma, abrem novas perspectivas para os adolescentes dessas regiões e principalmente, contribui para melhor desempenho na escola de origem tendo em vista que é realizado de forma simultânea com término do ensino fundamental II e ou o início do ensino médio.

Os locais onde são desenvolvidas as atividades contam com linhas de ônibus interurbanos que permitem que estudantes de outras regiões frequentem o curso preparatório assim como aqueles que moram em cidades próximas à capital. Há casos de quatro estudantes que estudavam em cidade situada a $80 \mathrm{~km}$ da capital frequentaram o curso de extensão e todos foram aprovados, sendo dois em 2016 e dois em 2017.

Em suma, os cursos preparatórios de extensão nos bairros afetados visam fornecer subsídios para que estes estudantes melhorem o desempenho escolar, conheçam as oportunidades existentes nos IFMS, e tenham êxito no processo de seleção da instituição.

Com isso, poderão conseguir acompanhar o curso técnico de nível médio, com consequentemente elevação da autoestima, e assim buscar alternativas para melhorarem as perspectivas de vida própria e em muitos casos também a dos seus familiares, mediante ao ingresso em uma instituição de ensino com formação profissionalizante e propedêutica de referência.

\section{CURSO PREPARATÓRIO PROPOSTO}

Em cada bairro existe uma instituição parceira, por exemplo um centro espírita, salão paroquial ou associação de bairro, que cede espaço para realização das aulas do curso preparatório e apoia com atividades administrativas e pedagógicas. $\mathrm{O}$ espaço cedido para realização das aulas conta com quadro negro, carteiras, ar condicionado e equipamentos auxiliares. Existe também uma secretaria para controle e registro dos estudantes.

O apoio pedagógico é realizado mediante o trabalho de trabalhadoras voluntárias que auxiliam da melhor forma possível as demandas e necessidades dos estudantes. Há também algumas pessoas voluntárias que auxiliam na parte administrativa e cuidam da infraestrutura, da merenda e ou lanches que também são ofertados gratuitamente.

Essas casas de assistência estão localizadas de forma que têm boas condições para atendimento da comunidade local. As instituições ficam respectivamente nas regiões:

- norte da cidade;

- sul da cidade;

- próximo ao aeroporto internacional.

\subsection{Metodologia e avaliação}

O curso é realizado mediante aulas de língua portuguesa, matemática e conhecimentos gerais nas segundas, quartas, quintas e/ou sextas-feiras. Desta forma, totalizam 3 dias de atividades por semana, com carga horária semanal média de 10,5 horas por semana. Ao final do semestre é dada uma prova de simulado para os estudantes para finalizarem a primeira parte do projeto, e aqueles que estiverem correspondendo com as perspectivas poderão se inscrever para fazer a segunda parte. Também há palestras descrevendo os cursos e infraestrutura do IFMS, mostrando-lhes que é possível buscar uma alternativa de vida por meio do estudo.

Tendo em vista que os estudantes vão ingressando ao longo do ano, são feitas provas de simulado intermediarias, com eles sendo observados e estimulados para permanecerem estudando e os professores procurarem atender, sempre que possível, às necessidades 
específicas, sempre no sentido de apoiar os estudantes a conviverem com os estudos de forma mais prazerosa, e que percebam a importância de desenvolver sua autoestima.

Normalmente, no primeiro semestre observa-se um desempenho escolar melhor por parte dos participantes e essa informação eles mesmos levam para os professores, assim como as dúvidas que tem em matemática e língua portuguesa, nas séries ou anos que estão frequentando no ensino fundamental. Tirar estas dúvidas e aproveitar para discutir com a sala o assunto em voga faz parte da metodologia aplicada.

As avaliações são realizadas mediante aplicação de simulados contendo questões dos conteúdos das séries que estão estudando, aplica-se a atividade e na sequência faz-se as correções e comentários das principais questões junto com a turma.

A avaliação de desempenho dos estudantes é mediante a análise da participação deles em sala de aula, assim como mediante a observação do desempenho nas provas de simulado que são aplicadas no decorrer do semestre.

Já para a avaliação da equipe de professores, normalmente é aplicado pelo público assistido um questionário com questões objetivas e discursivas onde os estudantes podem avaliar os professores quanto à didática, empatia, assiduidade, pontualidade e engajamento.

\subsection{Conteúdo Programático}

As três áreas de conhecimento englobam língua portuguesa, matemática e noções de conhecimentos gerais e atualidades, conforme descritas a seguir.

\section{Língua Portuguesa}

1. Leitura: Gêneros textuais; Linguagem verbal e não verbal; Tipos textuais; Narração; Descrição; Dissertação; Injunção; Coesão e coerência textual; Discurso direto e indireto; Variação linguística.

2. Fonologia: Ortografia; Acentuação gráfica; Reforma ortográfica de 2009.

3. Semântica: Significação das palavras; Sinônimos; Antônimos; Homônimos; Parônimos; Denotação e Conotação; Figuras de linguagem; Ambiguidade e polissemia; Inferência.

4. Morfologia: Classe gramatical das palavras; Flexão nominal e flexão verbal; Estrutura das palavras; Processos de formação das palavras.

5. Sintaxe: Frase, oração, período; tipos de frases; Funções sintáticas; Coordenação e subordinação; pontuação; crase; concordância verbal e nominal; regência verbal e nominal; colocação pronominal.

\section{Matemática}

1. Números e operações: números naturais e inteiros; múltiplos e divisores; números racionais; números irracionais; números reais; potência e raízes; operações com radicais; noções de função; notação científica; equações do $1^{\circ}$ e $2^{\circ}$ graus; problemas envolvendo funções de $1^{\circ}$ e $2^{\circ}$ graus; regra de 3 simples; porcentagem; probabilidade, juros simples, sistema métrico decimal.

2. Grandezas e medidas: ângulos; paralelismos; triângulos; quadriláteros; polígonos; área de polígonos e do círculo; unidades de medida;

3. Espaço e forma: razões e proporções; Teorema de Tales; semelhanças e congruências de triângulos; Teorema de Pitágoras; relação métrica do triângulo, retângulo; volume do bloco retangular; plano cartesiano;

4. Tratamento da Informação: coleta e organização de dados, tabelas e gráficos (leitura e interpretação). 
"Os desafios para formar hoje o engenheiro do amanhã"

\section{Conhecimentos gerais}

1. Tópicos relevantes e atuais de diversas áreas, tais como: economia, educação, política, cidadania, direitos humanos, tecnologia, artes e literatura.

\section{CONSIDERAÇÕES FINAIS}

Os cursos têm sido ministrados desde 2014, inicialmente em um bairro, e com o sucesso alcançado, mais unidades e parcerias foram abertas em diferentes bairros.

As turmas dos cursos preparatórios são pequenas, cerca de 20 alunos, mas muitos dos alunos têm conseguido passar no exame de seleção do IFMS, algo impensável anteriormente, ou no mínimo melhoraram seu gosto pelo estudo e seu desempenho escolar nas escolas de origem. Na Tabela 1 seguem alguns números para exemplificar a situação. A terceira unidade, perto do aeroporto, acabou de ser criada então ainda não há resultado dos ingressantes. Vale destacar que cada curso do IFMS tem turmas de 40 alunos, como são 3 cursos técnicos (eletrotécnica, mecânica e informática), há oferta anual de 120 vagas. Como a quantidade de alunos originários desses cursos preparatórios tem aumentado, isso mostra que o \% de vagas obtidos por eles aumentou muito, lembrando que sem os cursos não teriam conseguido passar no exame de seleção.

Tabela 1 - Quantidade de alunos aprovados por bairro, em cada processo seletivo por ano.

\begin{tabular}{c|c|c|c|}
\hline Ano de seleção & Zona Norte & Zona Sul & Aeroporto \\
\hline $2014 / 2015$ & 7 & --- & --- \\
\hline $2015 / 2016$ & 6 & 6 & --- \\
\hline $2016 / 2017$ & 12 & 5 & --- \\
\hline $2017 / 2018$ & 4 & 4 & --- \\
\hline $2018 / 2019$ & 13 & 7 & --- \\
\hline $2019 / 2020$ & 14 & 10 & --- \\
\hline
\end{tabular}

Fonte: Próprios autores

Os alunos que ingressaram têm sua vida transformada, e têm acompanhado com afinco os cursos técnicos, pois enxergam neles a possibilidade de melhoria de vida, literalmente.

Vários têm demonstrado interesse em continuar os estudos em cursos de engenharia ou da área de computação, e têm participado ativamente das oportunidades de trabalhos de pesquisa do campus.

Alguns alunos após ingressarem, também se tornam voluntários para ajudar em seu próprio bairro ou mesmo outros bairros, "infectando" os colegas de sala, que também acabam por ajudar.

Também são emitidos certificados, o que dá estimulo para os estudantes, tendo em vista que poderão incluir nos seus Curriculum Vitae. Quanto aos professores, principalmente os voluntários, é formalizada a contribuição para a carreira deles, além de ser notável o ganho de experiência e satisfação e senso de bem-estar. A certificação acaba contribuindo para credibilidade do curso de extensão e é um meio de atrair professores para a atividade. Alguns professores que desistiram devido a problemas particulares têm sido substituídos.

Os certificados aos estudantes voluntários são dados apenas aos tiveram frequência mínima de $60 \%$. Vale lembrar que são poucos estudantes devido à alta rotatividade observada ao longo dos anos dos mesmos no curso.

Com tudo isso, a experiência tem sido um sucesso para os professores e estudantes voluntários, mas principalmente como meio de fazer os IF atingirem a quem mais precisa. A tendência é no futuro crescerem em mais bairros as parcerias e os professores voluntários 
envolvidos, propiciando uma melhoria de vida a esses alunos, bem como uma melhoria do corpo discente do instituto, com alunos mais engajados, gratos e dedicados, envolvidos com as atividades extracurriculares do instituto, como por exemplo a pesquisa.

\title{
Agradecimentos
}

Os autores agradecem ao Instituto Federal de MS pela oportunidade de realizar este trabalho e contar com o auxílio dos gestores da instituição que sempre apoiaram a iniciativa, bem como agradecer o grupo de professores da instituição que estão envolvidos nesta ação como professores voluntários. Eles são muitos e dão a verdadeira sustentação para a continuidade deste trabalho.

Eles agradecem também suas famílias que auxiliam nesta tarefa diuturnamente. Ao engenheiro Paulo Cesar de Oliveira por ter ombreado essa tarefa desde o primeiro dia e em muitos momentos teve intuições e trabalhou sem reservas para que fosse atendida a quantidade de alunos.

Agradecimentos vão aos parceiros e suas instituições que fornecem a infraestrutura de sala e voluntários em cada bairro,

\section{REFERÊNCIAS}

BECHARA, Evanildo. Moderna Gramatica Portuguesa, 37 Ed, Rio de Janeiro: Lucerna, 2009.

ANDRINE, Alvaro; VASCONCELlOS, Maria Jose C. Praticando Matemática, Sao Paulo: Ed. do Brasil, 2008.

MENDES, Ivan Figueira. Matemática Para os Concursos, Rio de Janeiro: Ciência Moderna, 2010.

\section{ATRACTION AND RETENTION OF LOW-INCOME STUDENTS VIA PREPARATORY COURSES OF “AVANTE" PROJECT}

\begin{abstract}
This paper describes how low income students of poor neighborhoods had improved their chances for entering and staying at high-school level technical institutions. The actions taken in suburbs of the city of Campo Grande are presented, specifically the creation of a preparatory course to improve the chances and performance of students, mainly from public schools, with unfavorable economic conditions in three suburbs: the south, north and near the city's international airport. These suburbs present high crime rates, are affected by social problems like drug dealers and drug consumption, alcoholism and prostitution, amongst others. But even from these bad conditions, there are high potential students that need only the opportunity given by these preparatory courses to get access to better quality schools, like the Federal Institute of Education, Science and Technology (IFMS) and Military Schools. The chance to enter a well-structured learning system, with proper infrastructure for professional and intellectual development, as well as moral one, can bring them a significant improvement in the quality of life of the student and impact positively its family.
\end{abstract}

Keywords: Opportunity. Inclusion. Professional Education. Low Income Student. 